\title{
Genetic analysis of the cumulative pseudo-survival rate during lactation of Holstein cattle in Japan by using random regression models
}

\author{
O. Sasaki, ${ }^{, 1}$ M. Aihara, $†$ A. Nishiura, ${ }^{*}$ H. Takeda, ${ }^{*}$ and M. Satoh* \\ *NARO Institute of Livestock and Grassland Science, Tsukuba 3050901, Japan \\ †Livestock Improvement Association of Japan Inc., Tokyo 1350041, Japan
}

\begin{abstract}
Longevity is a crucial economic trait in the dairy farming industry. In this study, our objective was to develop a random regression model for genetic evaluation of survival. For the analysis, we used test-day records obtained for the first 5 lactations of 380,252 cows from 1,296 herds in Japan between 2001 and 2010; this data set was randomly divided into 7 subsets. The cumulative pseudo-survival rate (PSR) was determined according to whether a cow was alive (1) or absent (0) in her herd on the test day within each lactation group. Each lactation number was treated as an independent trait in a random regression multiple-trait model (MTM) or as a repeated measure in a random regression single-trait repeatability model (STRM). A proportional hazard model (PHM) was also developed as a piecewise-hazards model. The average $( \pm$ standard deviation) heritability estimates of the PSR at $365 \mathrm{~d}$ in milk (DIM) among the 7 data sets in the first (LG1), second (LG2), and third to fifth lactations (LG3) of the MTM were $0.042 \pm 0.007,0.070 \pm 0.012$, and 0.084 \pm 0.007 , respectively. The heritability estimate of the STRM was $0.038 \pm 0.004$. The genetic correlations of PSR between distinct DIM within or between lactation groups were high when the interval between DIM was short. These results indicated that whereas the genetic factors contributing to the PSR between closely associated DIM would be similar even for different lactation numbers, the genetic factors contributing to PSR would differ between distinct lactation periods. The average ( \pm standard deviation) effective heritability estimate based on the relative risk of the PHM among the 7 data sets was $0.068 \pm 0.009$. The estimated breeding values (EBV) in LG1, LG2, LG3, the STRM, and the PHM were unbiased estimates of the genetic trend. The absolute values of the Spearman's rank correlation coefficients between the EBV of the relative risk of the
\end{abstract}

Received November 24, 2014.

Accepted April 8, 2015.

${ }^{1}$ Corresponding author: sasa1@affrc.go.jp
PHM and the EBV of PSR at 365 DIM for LG1, LG2, LG3, and the STRM were 0.75, 0.87, 0.91, and 0.93, respectively. These results indicated that the EBV of PSR could predict the genetic contribution to survival. The EBV based on the PSR of the STRM was highly correlated with that of the MTM (0.83-0.96). Furthermore, the calculation load of the STRM was lighter than that of the MTM because the rank of the matrix of the STRM was smaller than that of the MTM. These results indicated that the STRM is an appropriate model for estimating survivability by using random regression models.

Key words: dairy cattle, genetic evaluation, survivability, random regression model

\section{INTRODUCTION}

The longevity of a cow is a crucial economic trait for increasing profits obtained from dairy herds (e.g., Gill and Allaire, 1976; VanRaden and Wiggans, 1995; Essl, 1998). Longevity is positively correlated with profits obtained from dairy herds (Weigel et al., 1995), and the economic weight of longevity is higher than that of other nonproductive traits of cows (Gill and Allaire, 1976). The use of a proportional hazard model (PHM) is more suitable for estimating the genetic ability for longevity than the use of a linear model because the estimates of a PHM fit the measurements well and are stable (Caraviello et al., 2004a,b). Because the PHM can appropriately accommodate censored data, consider time-dependent environmental effects, and manage the skewed distribution of the longevity trait, this model can be readily adapted to longevity data and is expected to provide accurate results (e.g., Ducrocq, 2002, 2005; Sewalem et al., 2010; Zavadilová et al., 2011). However, the disadvantage of using the PHM is that several steps are required to evaluate the genetic correlations between longevity and other continuous traits in the model (Tarrés et al., 2006). Holtsmark et al. (2009) reported that a multiple-lactation model is more accurate for the estimation of longevity at $365 \mathrm{~d}$ after the first calving when compared with the linear model, threshold model, and PHM. Like the PHM, the 
Table 1. Summary of raw data used for estimation of genetic parameters from each data set (Data1-7) and from the data sets used for verification (DATA2010 and DATA2006)

\begin{tabular}{|c|c|c|c|c|c|c|c|c|}
\hline \multirow[b]{2}{*}{ Data set } & \multirow[b]{2}{*}{$\begin{array}{l}\text { No. of } \\
\text { herds }\end{array}$} & \multicolumn{2}{|c|}{$\mathrm{RRM}^{1}$} & \multicolumn{2}{|c|}{$\mathrm{PHM}^{2}$} & \multicolumn{3}{|c|}{$\begin{array}{c}\text { No. of } \\
\text { removed records }\end{array}$} \\
\hline & & $\begin{array}{l}\text { No. of } \\
\text { cows }\end{array}$ & $\begin{array}{l}\text { No. of } \\
\text { related animals }\end{array}$ & $\begin{array}{c}\text { No. of } \\
\text { cows' sires }\end{array}$ & $\begin{array}{l}\text { No. of } \\
\text { related sires }\end{array}$ & LG1 & LG2 & LG3 \\
\hline Data1 & 188 & 56,109 & 106,825 & 2,809 & 3,839 & 5,790 & 7,847 & 20,089 \\
\hline Data2 & 206 & 61,701 & 114,876 & 2,847 & 3,858 & 6,730 & 8,769 & 22,507 \\
\hline Data3 & 202 & 60,052 & 115,335 & 2,868 & 3,902 & 6,253 & 8,629 & 21,666 \\
\hline Data6 & 167 & 47,305 & 91,191 & 2,691 & 3,614 & 4,834 & 6,714 & 17,321 \\
\hline Data7 & 167 & 49,867 & 94,783 & 2,624 & 3,571 & 5,325 & 7,228 & 17,973 \\
\hline Total & 1,296 & 380,252 & 649,068 & 4,357 & 5,949 & 40,075 & 54,158 & 137,491 \\
\hline DATA2010 & 665 & 193,876 & 340,721 & 3,962 & 5,290 & 20,082 & 27,252 & 70,558 \\
\hline DATA2006 & 665 & 130,169 & 261,864 & 2,984 & 4,258 & 10,486 & 13,804 & 36,456 \\
\hline
\end{tabular}

${ }^{1}$ Random regression model.

${ }^{2}$ Proportional hazard model.

${ }^{3}$ Lactation group $(\mathrm{LG} 1=$ first lactation; LG2 = second lactation; LG3 = third to fifth lactations).

random regression model (RRM) can handle censored data and can incorporate time-dependent environmental effects (Veerkamp et al., 2001). Moreover, the RRM can be used to estimate the genetic correlation between longevity and other traits directly. Therefore, the RRM would be useful for evaluating longevity. However, few reports have demonstrated an adaptation of the RRM for analyzing longevity (Veerkamp et al., 2001; Jamrozik et al., 2008).

In this study, our aim was to compare estimates of the genetic ability for survival derived from the RRM and PHM, and to investigate the variability and reliability of the estimates obtained from the RRM.

\section{MATERIALS AND METHODS}

\section{Data}

Data sets containing the test-day records from 2001 to 2010 were obtained from the Livestock Improvement Association of Japan (http://liaj.lin.gr.jp/) and the National Livestock Breeding Center (http://www. nlbc.go.jp/english/index.html). The first calving ages of cows in this data set were between 18 and 35 mo. The data for 1,296 herds, which included 5 or more third-lactation cows on every test day from 2006 to 2010 , were extracted from this data set. All data of the first 5 lactation test-day records between 6 and 455 DIM were collected from these herds. The entire data set was divided into 7 subsets randomly with respect to the herd to fit our computational limit, and the genetic parameters for survival were estimated in each subset independently (Data1-7; Table 1). The day of removal of a cow from her herd was considered the last test day of the cow when the interval between the last test day of the cow and the last test day of her herd was more than $120 \mathrm{~d}$. When the interval between the last test day of the cow and the last test day of her herd was less than $120 \mathrm{~d}$, the last test day of the cow was considered the day of censoring. When a cow was alive until 2011, or when her herd was withdrawn from the herd test, the cow had a censored record. The calving records of a cow that was removed before the first test day of the lactation were not included in the data set. The removal day of this cow was the dry-off day of prior parity. Because this cow's test-day records in the raising period and in the dry period were not obtained, the lifespan of the data indicated the length of the production period.

In the RRM, records at a test day within a lactation were used to calculate the cumulative pseudo-survival rate (PSR). Specifically, the PSR value was determined according to whether the cow was alive (1) or absent (0) in her herd at the test day within the lactation. The PSR record of the last test day before the removal day of a cow was coded as 0 , and the subsequent test-day records in the same parity of the cow were coded as 0 until 455 DIM (case 1 in Figure 1). The PSR record of a cow in the parities before the parity at removal was coded as 1, and the last test day before the dry-off day of a cow was considered the day of censoring (case 2 in Figure 1). The PSR record of the day of censoring of a cow was coded as 1 , and the subsequent test-day records in the same parity of the cow were considered missing. When a cow was dried off after DIM 455, the last test day of the cow before DIM 455 was considered the day of censoring and coded as 1 (case 3 in Figure 1). When a cow was removed after 455 DIM, the last test 

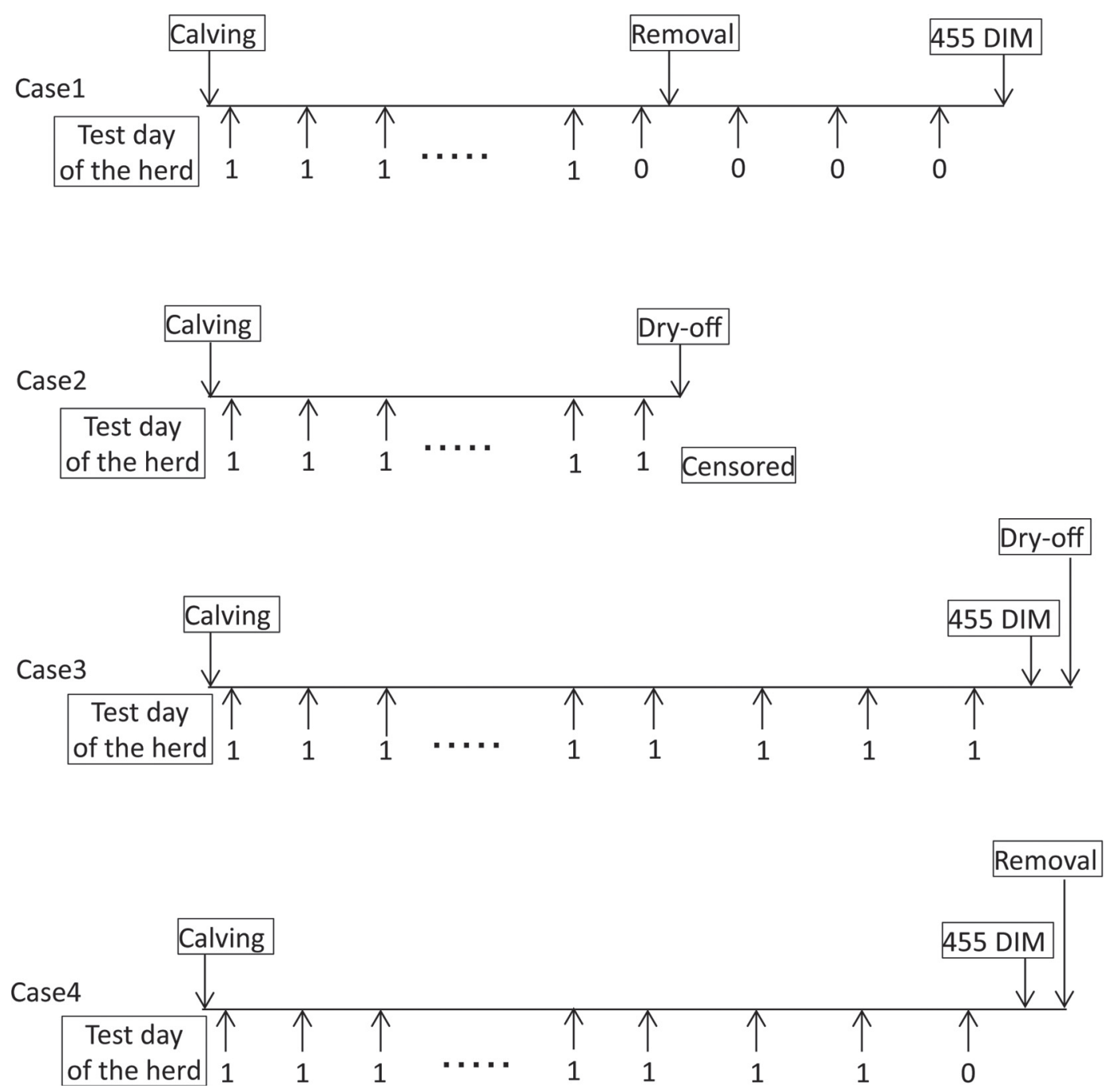

Figure 1. Recording method of the cumulative pseudo-survival rate during lactation for the random regression model.

day of the cow before 455 DIM was considered to be the removal day, and it was coded as 0 (case 4 in Figure 1). The PSR records in the parities subsequent to the removal parity were considered missing. The related animals in the pedigree record were the cows for which PSR records were available and the ancestors traced back to 3 generations based on those cows (Table 1).

In the PHM, the lifespan in each parity was calculated as the number of days from the 6th day after calving to the day of removal. When a new lactation started, the last test day before the dry-off day of the cow was considered the day of censoring. When the cow was dried off after 455 DIM, the lifespan of the cow was considered to be $450 \mathrm{~d}$, and such data were considered the censored data. When a cow was removed after 455 DIM, the cow was considered to be removed at 455 DIM. The records in the parity subsequent to the removal parity were considered missing. The pedigree was traced back to 3 generations based on the PSR records obtained for each cow. The records of the sire and maternal grandsire (MGS) of the cows in this pedigree data were used for the PHM analysis.

\section{$R R M$}

In the multiple-trait animal model for random regression (MTM), different lactation groups were treated as correlated traits. The lactation groups of the first lactation (LG1), second lactation (LG2), and third to fifth lactations (LG3) were considered the first, second, and third traits, respectively. In LG3, the observations of third to fifth lactation were treated as repeated observations. The analysis of the MTM was based on a 3-trait model (Caccamo et al., 2008): 


$$
\begin{aligned}
\mathrm{y}_{d i j k l t}= & \sum_{q=0}^{4} \operatorname{RPA}_{i t q} \varphi_{q}(d)+\sum_{q=0}^{2} \mathrm{hys}_{j t q} \varphi_{q}(d) \\
& +\sum_{q=0}^{2} \mathrm{a}_{k t q} \varphi_{q}(d)+\sum_{q=0}^{2} \operatorname{pe}_{k l t q} \varphi_{q}(d)+\mathrm{e}_{d i j k l t},
\end{aligned}
$$

where $\mathrm{y}_{\text {dijklt }}$ is the observation of PSR of cow $k$ exhibiting trait $t$ at DIM $d$, and $\mathrm{RPA}_{i t q}$ is the $q$ th fixed regression coefficient of the region-parity-age of calving group $i$ with trait $t(q=0-4)$. The region classes were Hokkaido and other regions in Japan. The age groups at calving were divided into 5 classes in each parity. The hys $j t q$ is the $q$ th random regression coefficient of the herd-year-season group $j$ with trait $t(q=0-2)$. The season was divided into 4 classes: from January to March, April to June, July to September, and October to December. The $\mathrm{a}_{k t q}$ is the $q$ th additive genetic random regression coefficient of cow $k$ exhibiting trait $t$ ( $q$ $=0-2)$. The $\mathrm{pe}_{k l t q}$ is the $q$ th permanent environmental random regression coefficient of cow $k$ within lactation $l$ with trait $t(l=1-5, q=0-2)$. The $\mathrm{e}_{\text {dijklt }}$ is the residual random effect for each observation. The $\varphi_{q}(d)$ is the $q$ th Legendre polynomial at DIM $d$. The variance and covariance were defined as follows:

$$
\operatorname{var}\left[\begin{array}{l}
\mathbf{a} \\
\mathbf{p} \\
\mathbf{h} \\
\mathbf{e}
\end{array}\right]=\left[\begin{array}{cccc}
\mathbf{G} \otimes \mathbf{A} & 0 & 0 & 0 \\
0 & \mathbf{Q} \otimes \mathbf{I}_{\mathbf{c}} & 0 & 0 \\
0 & 0 & \mathbf{H} \otimes \mathbf{I}_{\mathbf{h}} & 0 \\
0 & 0 & 0 & \mathbf{R} \otimes \mathbf{I}_{\mathbf{n}}
\end{array}\right]
$$

where $\mathbf{a}, \mathbf{p}$, and $\mathbf{h}$ are vectors of the regression coefficients for the additive genetic effect, permanent environmental effect, and herd-year-season effect, respectively; $\mathbf{e}$ is a vector of the residual effect; and $\mathbf{G}, \mathbf{Q}$, and $\mathbf{H}$ are the (co)variance matrices for the additive genetic, permanent environmental, and herd-year-season regression coefficients, respectively. $\mathbf{R}$ is the residual variance diagonal matrix. The residual variances were divided into 5 intervals $(6-95,96-185,186-275,276-365$, and 366-455 DIM). The off-diagonal elements between the traits of $\mathbf{Q}$ and $\mathbf{R}$ were assumed to be zero because the removal observation coded as 0 for each cow existed only in the removal parity. The $\mathbf{A}$ is the additive genetic relationship matrix between animals, and $\mathbf{I}_{\mathbf{c}}, \mathbf{I}_{\mathbf{h}}$, and $\mathbf{I}_{\mathbf{n}}$ are identity matrices.

In the single-trait repeatability animal model for random regression (STRM), the first to fifth lactations were treated as repeated records. The analytical model of the STRM was based on equation [1] of the MTM:

$$
\begin{aligned}
\mathrm{y}_{d i j k l}= & \sum_{q=0}^{4} \operatorname{RPA}_{i q} \phi_{q}(d)+\sum_{q=0}^{2} \operatorname{hys}_{j q} \phi_{q}(d) \\
& +\sum_{q=0}^{2} \mathrm{a}_{k q} \phi_{q}(d)+\sum_{q=0}^{2} \operatorname{pe}_{k l q} \phi_{q}(d)+\mathrm{e}_{d i j k l},
\end{aligned}
$$

where $\mathrm{y}_{\text {dijkl }}$ is the observation of PSR of cow $k$ at DIM $d, \mathrm{RPA}_{i q}$ is the $q$ th fixed regression coefficient of the region-parity-age of calving group $i(q=0-4)$, hys $_{j q}$ is the $q$ th random regression coefficient of the herd-yearseason group $j(q=0-2), \mathrm{a}_{k q}$ is the $q$ th additive genetic random regression coefficient of cow $k(q=0-2)$, pe $\mathrm{p}_{k l q}$ is the $q$ th permanent environmental random regression coefficient of cow $k$ within lactation $l(l=1-5, q=$ $0-2)$, and $\mathrm{e}_{\text {dijkl }}$ is the residual random effect for each observation. The variance and covariance components were same as those in equation [2] of the MTM.

The variances of the RRM in Data1-7 were estimated separately using the computer software gibbs3f90 (Misztal et al., 2002). The first 100,000 Gibbs samples were discarded as burn-ins. Convergence was checked by visually inspecting the graph of the next 200,000 samples, and these 200,000 samples after the burn-in period were used for calculating the posterior means for (co)variance components and heritabilities at test d 6 to 455 DIM. When $\boldsymbol{\Phi}_{\boldsymbol{d}}^{\prime}=\left[\varphi_{0}(\mathrm{~d}) \varphi_{1}(\mathrm{~d}) \varphi_{0}(\mathrm{~d})\right]^{\prime}$, the matrices for daily additive genetic (co)variance $\left(\hat{\mathbf{G}}_{\boldsymbol{d}}\right)$, permanent environmental variance $\left(\hat{\mathbf{Q}}_{\boldsymbol{d}}\right)$, and herd-yearseason effect (co)variance $\left(\hat{\mathbf{H}}_{\boldsymbol{d}}\right)$ at $d$ DIM were defined as $\hat{\mathbf{G}}_{d}=\Phi_{d}^{\prime} \hat{\mathbf{G}} \Phi_{d}, \hat{\mathbf{Q}}_{d}=\Phi_{d}^{\prime} \hat{\mathbf{Q}} \Phi_{d}$, and $\hat{\mathbf{H}}_{d}=\boldsymbol{\Phi}_{d}^{\prime} \hat{\mathbf{H}} \Phi_{d}$, respectively. The daily heritability at $d \operatorname{DIM}\left(\hat{\mathrm{h}}_{d}^{2}\right)$ was defined as follows:

$$
\hat{\mathrm{h}}_{d}^{2}=\frac{\hat{\sigma}_{\mathrm{g}_{d}}^{2}}{\hat{\sigma}_{\mathrm{g}_{d}}^{2}+\hat{\sigma}_{\mathrm{p}_{d}}^{2}+\hat{\sigma}_{\mathrm{h}_{d}}^{2}+\hat{\sigma}_{\mathrm{r}_{d}}^{2}},
$$

where $\hat{\sigma}_{\mathrm{g}_{d}}^{2}, \hat{\sigma}_{\mathrm{p}_{d}}^{2}, \hat{\sigma}_{\mathrm{h}_{d}}^{2}$, and $\hat{\sigma}_{\mathrm{r}_{d}}^{2}$ are the additive genetic, permanent environmental, herd-year-season, and residual variance at $d$ DIM, respectively. The daily genetic correlations between $d 1$ and $d 2 \operatorname{DIM}\left(\hat{\mathrm{r}}_{\mathrm{g}_{d 1 d 2}}\right)$ were estimated, according to equation [5], for 6 DIM and once every $30 \mathrm{~d}$ from 35 to 455 DIM within and between lactations. The matrix for the genetic covariance estimates between $d 1$ and $d 2$ DIM was $\hat{\mathbf{C}}_{\boldsymbol{d} 1 \boldsymbol{d} 2}=\boldsymbol{\Phi}_{\boldsymbol{d} 1}^{\prime} \hat{\mathbf{G}} \boldsymbol{\Phi}_{\boldsymbol{d} 2}$.

$$
\hat{\mathrm{r}}_{\mathrm{g}_{d 1 d 2}}=\frac{\widehat{\operatorname{Cov}}_{d 1 d 2}}{\sqrt{\hat{\sigma}_{\mathrm{g}_{d 1}}^{2} \times \hat{\sigma}_{\mathrm{g}_{d 2}}^{2}}}
$$


where $\widehat{\operatorname{Cov}}_{d 1 d 2}$ is the genetic covariance between $d 1$ and $d 2$ DIM.

\section{PHM}

The following model was applied to the estimation of the genetic parameters in Data1-7 for the PHM:

$\lambda(\delta)=\lambda_{0, p}(\delta) \exp \left[\mathrm{RPA}_{i}+\operatorname{hys}_{j}\left(\delta^{\prime}\right)+\operatorname{sire}_{k}+0.5 \mathrm{mgs}_{l}\right]$,

where $\lambda(\delta)$ is a hazard function of a cow at $d$ DIM $(\delta=$ $d-5$ ), and $\lambda_{0, p}(\delta)=\lambda_{p} \rho_{p}\left(\lambda_{p} \delta\right)^{\rho_{p}}$ is the Weibull baseline hazard function featuring the scale parameter $\lambda_{p}$ and the shape parameter $\rho_{p}$ specific to the region-paritylactation period group $p$. The lactation period was divided into 2 classes: from 6 to 255 DIM (LP1) and from 266 to 455 DIM (LP2). The $\mathrm{RPA}_{i}$ is the fixed effect of region-parity-age for calving group $i$, and $\operatorname{hys}_{j}(\delta$ ') is the time-dependent random effect of herd-year-season group $j$ at calendar time $\delta^{\prime}$. This effect is assumed to follow a log-gamma distribution $\left(\gamma_{\text {hys }}\right)$, where $\sigma_{\text {hys }}^{2}=$ $\boldsymbol{\Psi}^{(1)}\left(\gamma_{\text {hys }}\right)$, and $\boldsymbol{\Psi}^{(1)}\left(\gamma_{\text {hys }}\right)$ is a trigamma function of $\gamma_{\text {hys }}$. The sire $_{k}+0.5 \mathrm{mgs}_{l}$ is the additive genetic effect of the cow's sire and MGS, which follows a multivariate normal distribution featuring a mean zero and variance $\mathbf{A} \sigma_{\mathrm{s}}^{2}$, where $\sigma_{\mathrm{s}}^{2}$ is the variance among sires and $\mathbf{A}$ is the additive genetic relationship matrix between sires. The effective heritability was estimated as described in Yazdi et al. (2002) and Calus et al. (2005):

$$
\hat{\mathrm{h}}_{\mathrm{s}, \mathrm{eff}}^{2}=\frac{4 \hat{\sigma}_{\mathrm{s}}^{2}}{1.25 \hat{\sigma}_{\mathrm{s}}^{2}+\hat{\sigma}_{\mathrm{hys}}^{2}+1} .
$$

The parameters of the PHM were estimated using The Survival Kit version 6.1 software (Ducrocq et al., 2010).

\section{Validation of Genetic Trends and Reliability of Genetic Ability Estimates for PSR}

The data set used for validating the estimated parameters of the RRM and PHM was established from the entire data set comprising Data1-7 by selecting 665 herds at random to fit our computational limit (DATA2010: Table 1). In the RRM, the EBV at $65,95,155,305,365$, and 455 DIM were estimated in DATA2010. These analyses were performed using the averages of genetic parameter estimates obtained across Data1-7 in the computer software blupf90 (Misztal et al., 2002). The ETA of the relative risk (RR) of the
PHM was estimated using The Survival Kit version 6.1 software (Ducrocq et al., 2010). Twice the ETA of the $\mathrm{RR}$ was considered as the EBV of the RR. The data set of records from 2001 to 2006 obtained from DATA2010 was used for the validation test (DATA2006: Table 1). Using the same method as that applied for DATA2010, the EBV of the RRM and PHM were estimated for DATA2006. A third method, described by Boichard et al. (1995), was used for validating the estimation of genetic trends of the genetic ability estimates:

$$
\mathbf{v}=\mathbf{X g}+\mathbf{u b}+\mathbf{t} \delta+\mathbf{e}
$$

where $\mathbf{v}$ is the vector of EBV in DATA2010 and $\mathbf{u}$ is the vector of EBV in DATA2006. These EBV were obtained from sires with 30 or more recorded daughters in DATA2006. The $\mathbf{g}$ is the fixed effect of birth-year of a sire, and $\mathbf{X}$ is the incidence matrix. The coefficient $\mathrm{b}$ represents a conversion factor between DATA2006 and DATA2010. The $\mathbf{t}$ is a parameter that depends on the change in the number of daughters of each sire when comparing DATA2006 to DATA2010, the coefficient $\delta$ is an estimate of the bias in the estimate of the annual genetic trend, and $\mathbf{e}$ is a vector of residuals. The analysis was performed using the GLM procedures of SAS (SAS Institute Inc., 2004).

In the RRM, the reliabilities of the EBV of daily PSR of a sire with 30 or more recorded daughters in DATA2010 were estimated using the method of Liu et al. (2001, 2004). This reliability approximation method is based on the concept of the multiple-trait effective daughter contribution for the RRM. In the PHM, the reliability of the EBV of the same sires as those considered in the RRM was estimated using the method of Yazdi et al. (2002). In this model, the predicted reliability from the Weibull models $\left(\mathrm{R}_{\text {wei }}\right)$ is calculated using the number of uncensored progeny $\left(\mathrm{n}_{\text {uncen }}\right)$ and the sire variance, as shown in equation [9]:

$$
\mathrm{R}_{\mathrm{wei}}=\frac{\mathrm{n}_{\text {uncen }}}{\mathrm{n}_{\text {uncen }}+\frac{1}{\sigma_{\mathrm{s}}^{2}}} \text {. }
$$

The EBV of PSR at 305, 365, and 455 DIM of LG1, LG2, LG3, and the STRM for sires with 30 or more recorded daughters in DATA2010 were selected. The EBV of the RR for these same sires were selected. The absolute values of the Spearman's correlation coefficients between all pairs of these EBV were calculated using the CORR procedures of SAS (SAS Institute Inc., 2006). 


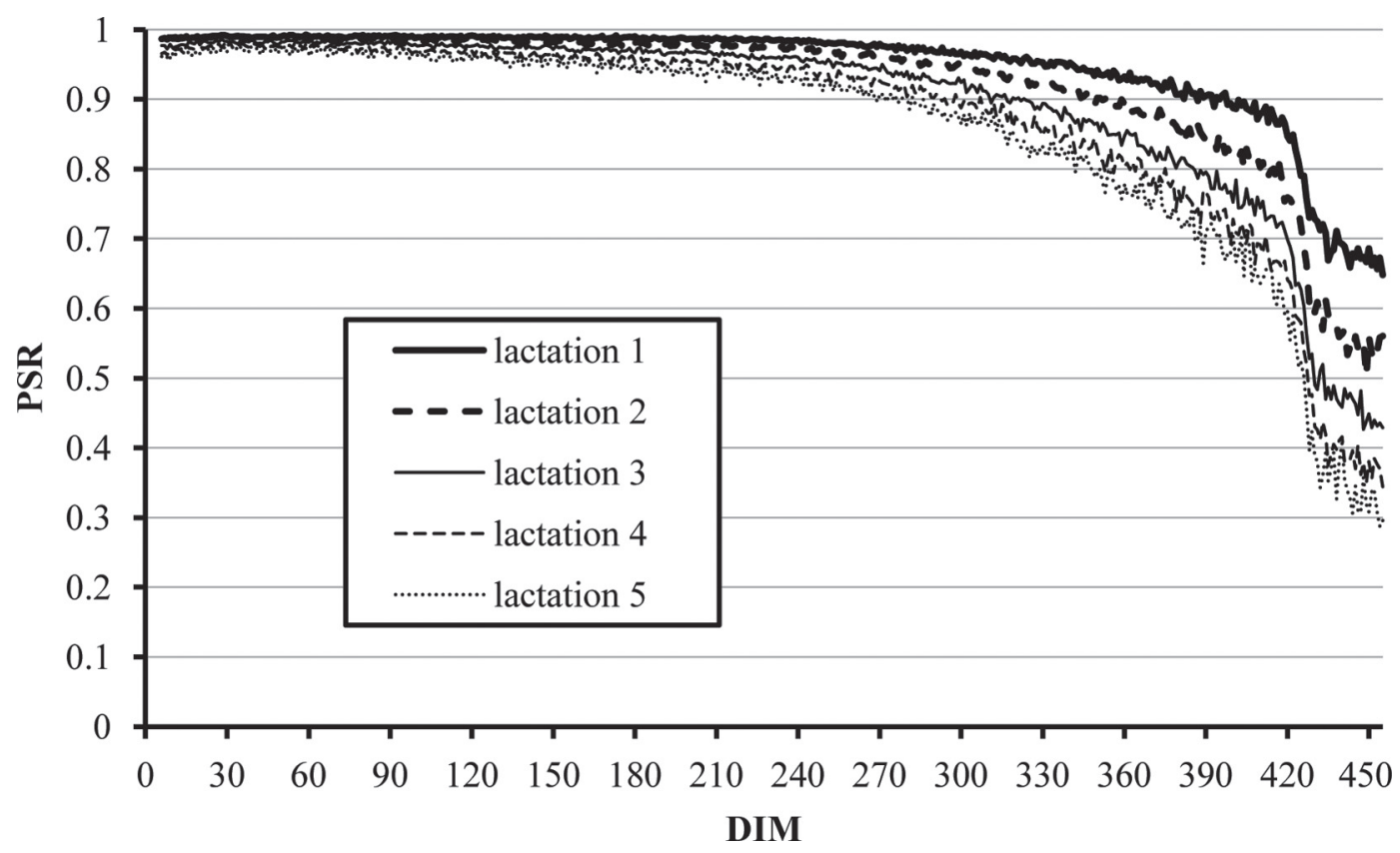

Figure 2. Change of the cumulative pseudo-survival rate (PSR) in each lactation group.

\section{RESULTS}

\section{RRM}

The average PSR decreased at late DIM, and the decrement was rapid after 250 DIM (Figure 2). The PSR in the later parities decreased more rapidly than those in the earlier parities. The PSR from 426 to 455 DIM were low because 455 DIM was considered to be the last test day for cows that were removed from the herd after 455 DIM.

In the MTM, the variances of the additive genetic effect, permanent environmental effect, herd-year-season effect, and residual effect of PSR increased with an increase in DIM (Figures 3a, 3b, and 3c). These variances increased more rapidly during the late lactation period than during the early lactation period; specifically, these variances were largest in LG3, followed by LG2 and LG1. The averages $( \pm \mathrm{SD})$ of the constant regression coefficient variance for the additive genetic effect across Data1-7 in LG1, LG2, and LG3 were 13.26 $\pm 2.67,28.56 \pm 3.85$, and $52.57 \pm 3.60$, respectively. The averages $( \pm \mathrm{SD})$ of the linear regression coefficient variance for the additive genetic effect were $13.58 \pm$ $2.55,40.12 \pm 8.90$, and $66.44 \pm 9.88$, respectively. Furthermore, the averages $( \pm \mathrm{SD})$ of the quadratic regression coefficient variance for the additive genetic effect were $3.43 \pm 0.94,8.13 \pm 1.69$, and $10.73 \pm 1.36$, respectively. The genetic covariances between each lactation group pair increased with an increase in DIM (Figure $3 \mathrm{~d})$. These covariances increased more rapidly during the late lactation period than during the early lactation period, and the covariances were largest between LG2 and LG3, followed by between LG1 to LG3 and between LG1 and LG2. The $\hat{\mathrm{h}}_{d}^{2}$ values of PSR were lowest in LG1 among the lactation groups (Figure 3e). These $\hat{\mathrm{h}}_{d}^{2}$ values in LG2 were similar to those of LG3 until 321 DIM, and thereafter were higher in LG3 than in LG2 $(P<0.05)$. The averages $( \pm \mathrm{SD})$ of $\hat{\mathrm{h}}_{d}^{2}$ across Data1 -7 in LG1, LG2, and LG3 at 305 DIM were $0.036 \pm 0.006$, $0.056 \pm 0.008$, and $0.064 \pm 0.005$, respectively, whereas those at 365 DIM were $0.042 \pm 0.007,0.070 \pm 0.012$, and $0.084 \pm 0.007$, and at 455 DIM were $0.033 \pm 0.007$, $0.062 \pm 0.013$, and $0.081 \pm 0.007$, respectively. The genetic correlation estimates of PSR between lactation groups were low in the early DIM, and then increased until 45 DIM (Figure 3f) and remained stable thereafter. These genetic correlations were highest between LG2 and LG3, followed by between LG1 and LG2 and between LG1 and LG3. The standard deviations of these genetic correlations among Data1-7 between LG1 and LG2, between LG1 and LG3, and between LG2 and LG3 were 0.049 to $0.204,0.094$ to 0.120 , and 0.021 to 0.259 , respectively.

In the STRM, the variances of the additive genetic effect and herd-year-season effect of PSR (Figure 4a) were between those estimated for LG1 and LG2 (Figures $3 \mathrm{a}$ and $3 \mathrm{~b})$. The averages $( \pm \mathrm{SD})$ of the constant, linear, and quadratic regression coefficient variances calculated for the additive genetic effect of the STRM across Data1-7 were $13.26 \pm 2.67,28.56 \pm 3.85$, and 
(a) Variances of LG1

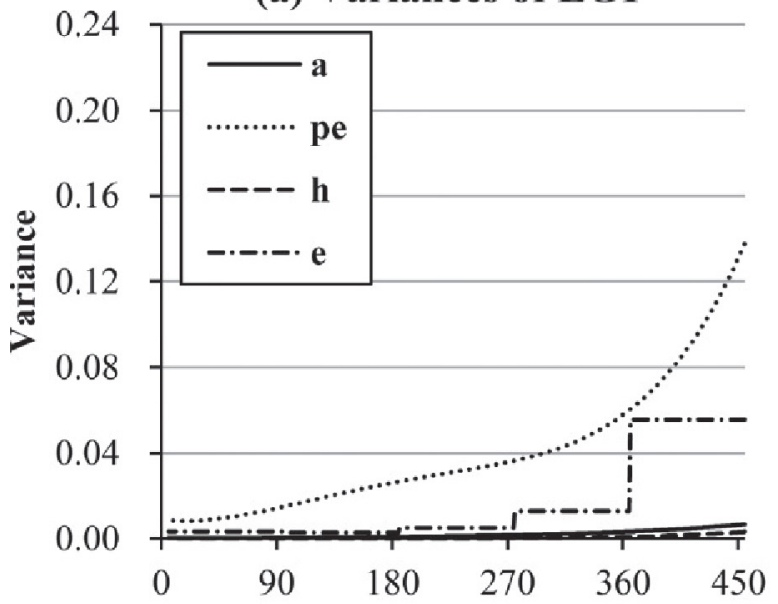

(c) Variances of LG3

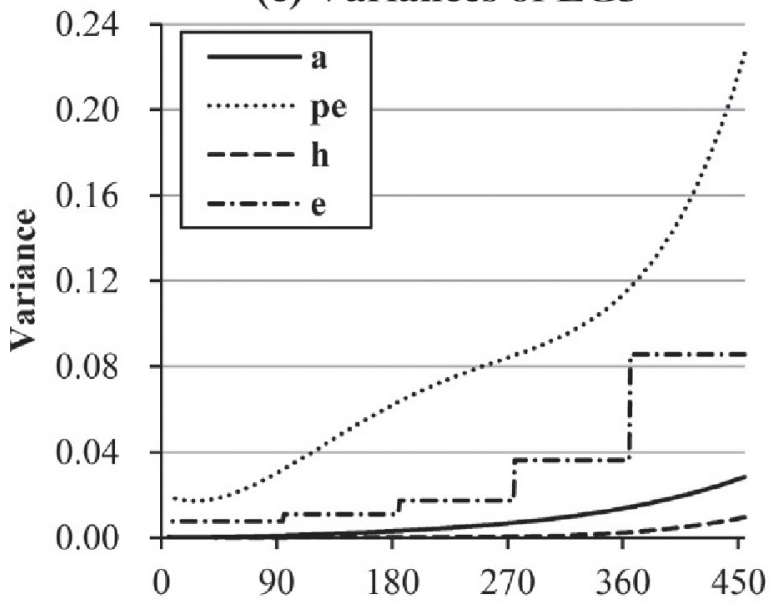

(e) Heritability

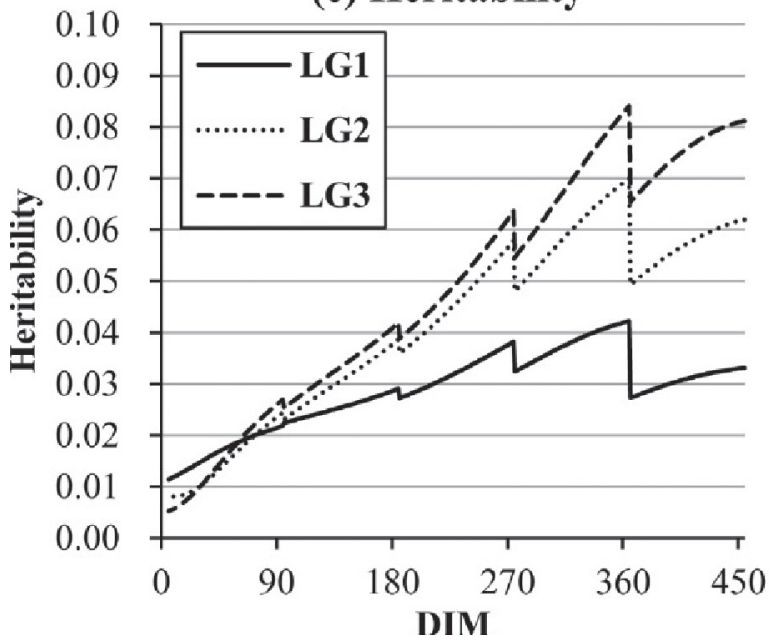

(b) Variances of LG2

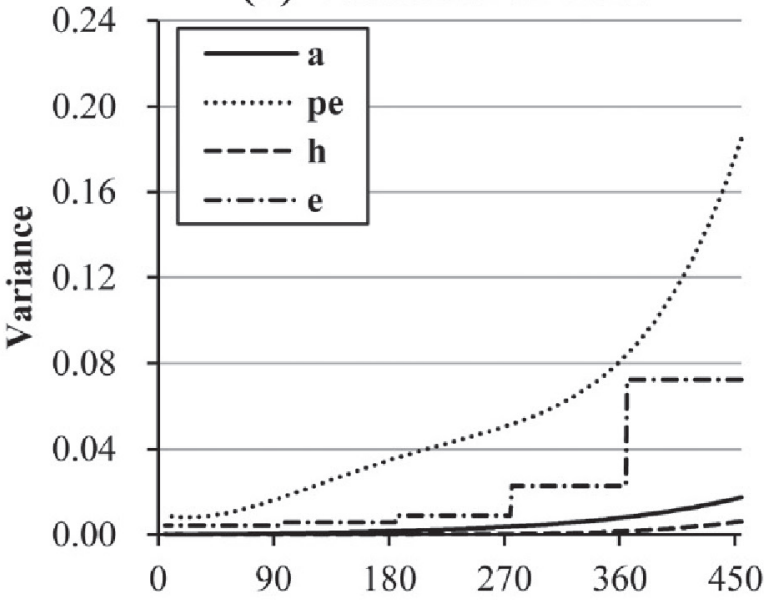

(d) Genetic covariances

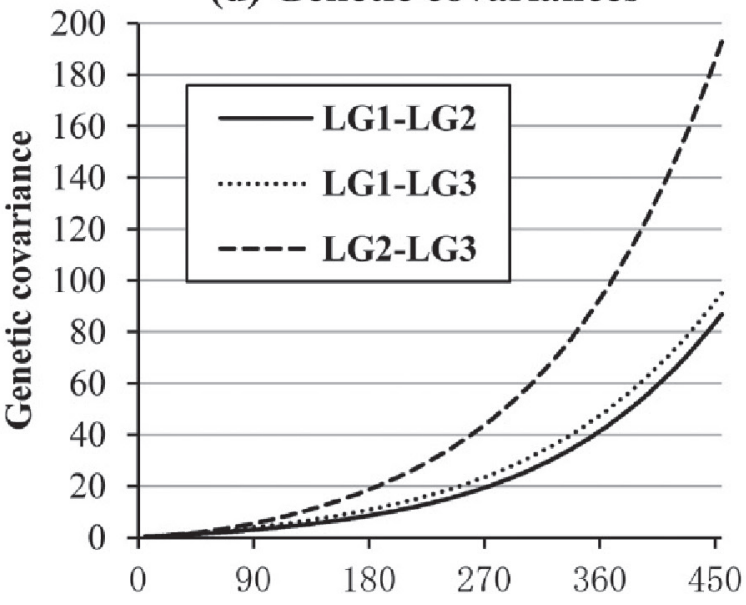

(f) Genetic correlation

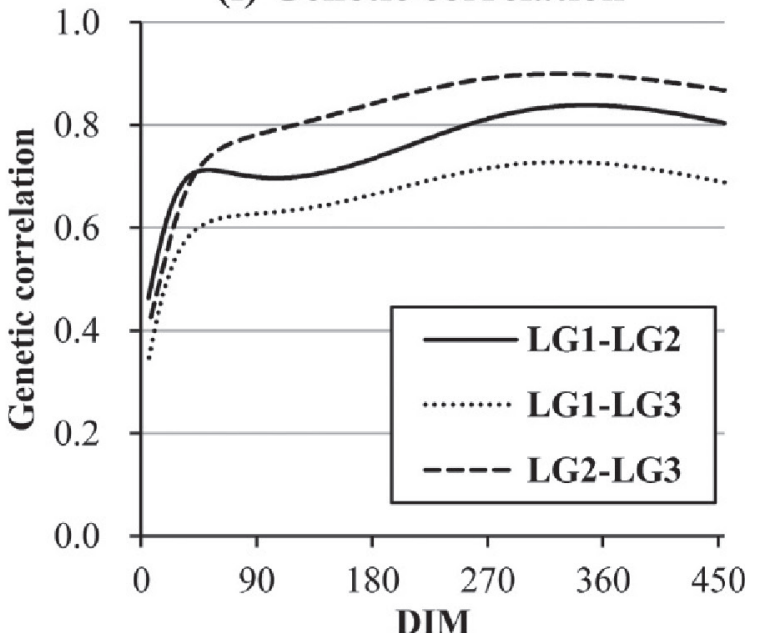

Figure 3. Genetic parameter estimates of the cumulative pseudo-survival rate within a lactation group determined using the multiple-trait animal model for random regression. (a) Estimated variances of additive genetic effect (a), permanent environmental effect within a lactation period (pe), herd-year-season effect (h), and residual effect (e) in the first lactation (LG1). (b) The same variances as in (a) in the second lactation (LG2). (c) The same variances as in (a) in the third to fifth lactations (LG3). (d) Estimated genetic covariances between LG1 and LG2 (LG1-LG2), LG1 and LG3 (LG1-LG3), and LG2 and LG3 (LG2-LG3). (e) Heritability estimates in LG1, LG2, and LG3. (f) Estimated genetic correlations between LG1 and LG2 (LG1-LG2), LG1 and LG3 (LG1-LG3), and LG2 and LG3 (LG2-LG3). 
(a) Variances

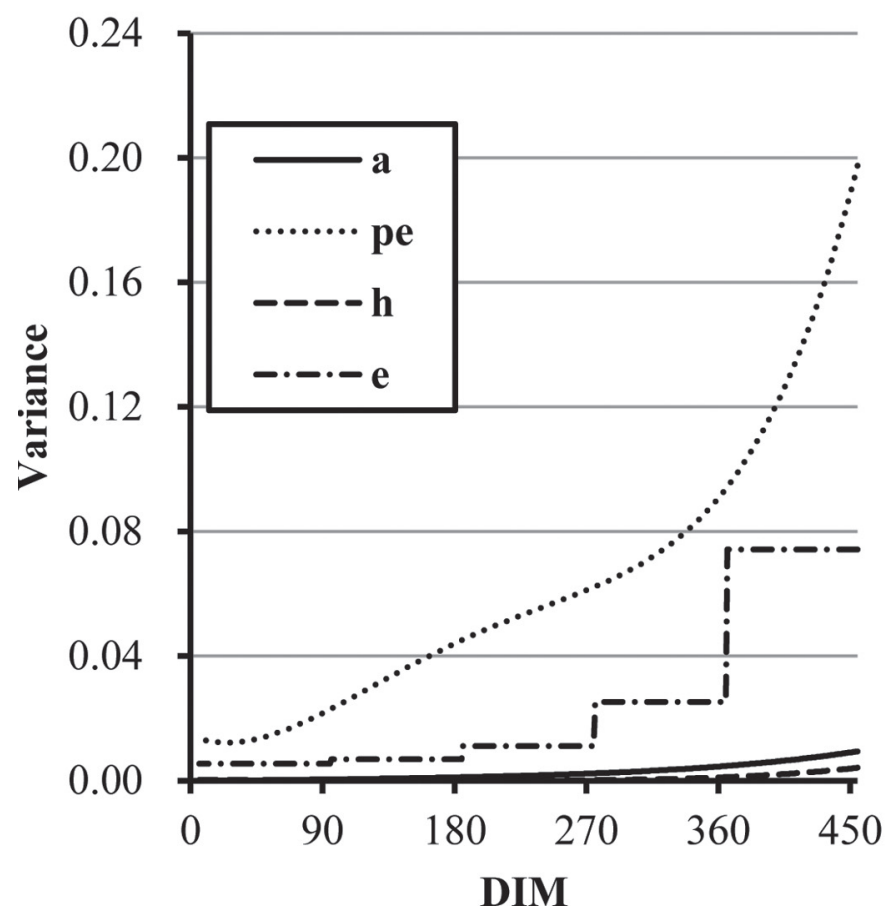

(b) Heritability

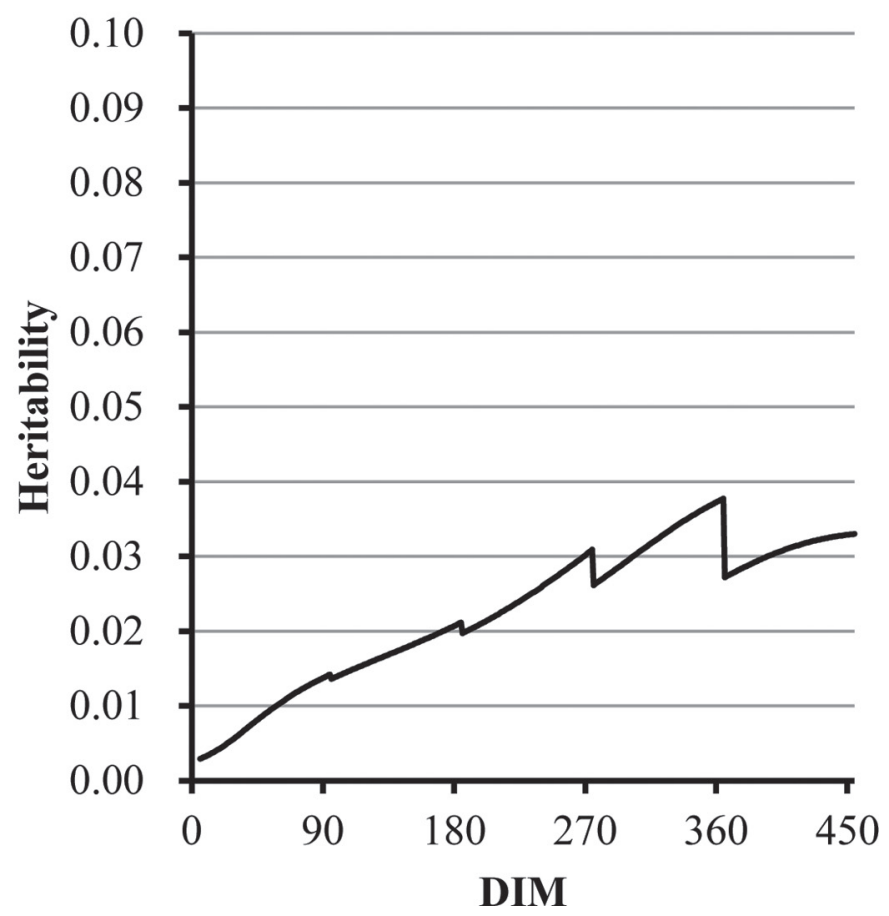

Figure 4. Genetic parameter estimates of the cumulative pseudo-survival rate from the single-trait repeatability animal model for random regression (STRM). (a) The variances of the additive genetic effect (a), permanent environmental effect within a lactation period (pe), herdyear-season effect (h), and residual effect (e). (b) Heritability estimates.

$52.57 \pm 3.60$, respectively. The variances of the permanent environmental effect and the residual effect of the STRM were similar to those of LG2. The $\hat{\mathrm{h}}_{d}^{2}$ values of PSR were lower in the STRM than in LG1, LG2, and LG3 before 144 DIM $(P<0.05)$, and were thereafter similar to those of LG1 (Figure 4b). The standard deviations of the $\hat{\mathrm{h}}_{d}^{2}$ of PSR in the STRM across Data1-7 were in the range of 0.001 to 0.004 . The average $( \pm \mathrm{SD})$ $\hat{\mathrm{h}}_{d}^{2}$ values at 305,365 , and 455 DIM of the STRM were $0.030 \pm 0.003,0.038 \pm 0.004$, and $0.033 \pm 0.004$, respectively, which were similar to those of LG1.

Figure 5 shows the contour plots of the genetic correlation estimate matrices of PSR between pairs of DIM in the MTM and STRM. In both the MTM and the STRM, the genetic correlations were higher for pairs of DIM that were closer together than for pairs farther apart. Specifically, the genetic correlation estimates were greater than 0.9 when the intervals were less than $120 \mathrm{~d}$. In the MTM, the genetic correlations between different parities were high when the DIM were close to each other and were higher in late lactation periods than in the early lactation periods. The maximum values of these genetic correlations were observed between 305 and 335 DIM, and were 0.84 between LG1 and
LG2, 0.73 between LG1 and LG3, and 0.90 between LG2 and LG3.

\section{PHM}

Table 2 shows the averages of the Weibull parameters $\lambda_{p}$ and $\rho_{p}$ across Data1-7 in each region-parity-lactation period. The average $\lambda_{p}$ was higher in LP2 than in LP1 $(P<0.01)$, and was higher in later parity than in early parity $(P<0.01)$. The average $\rho_{p}$ was also higher in LP2 than in LP1 $(P<0.01)$, and the $\rho_{p}$ of LP2 was highest in LG1 among the lactation groups $(P<0.01)$. The average $( \pm \mathrm{SD}) \hat{\gamma}_{\text {hys }}, \hat{\sigma}_{\text {hys }}^{2}$, and $\hat{\sigma}_{\mathrm{s}}^{2}$ values across Data1-7 were $4.51 \pm 0.044,0.251 \pm 0.027$, and 0.0217 \pm 0.0026 , respectively. The average $( \pm \mathrm{SD}) \hat{\mathrm{h}}_{\mathrm{s}, \mathrm{eff}}^{2}$ of the PHM across Data1-7 was $0.068 \pm 0.009$.

\section{Validation of Genetic Trends and Reliability of Genetic Ability Estimates for PSR}

In DATA2006, we found that 91, 92, and 292 sires had 30 or more daughters in LG1, LG2, and LG3, respectively. The numbers of these sires in the STRM and PHM were both 292 . Because the $\delta$ values of equation 
(a) MTM
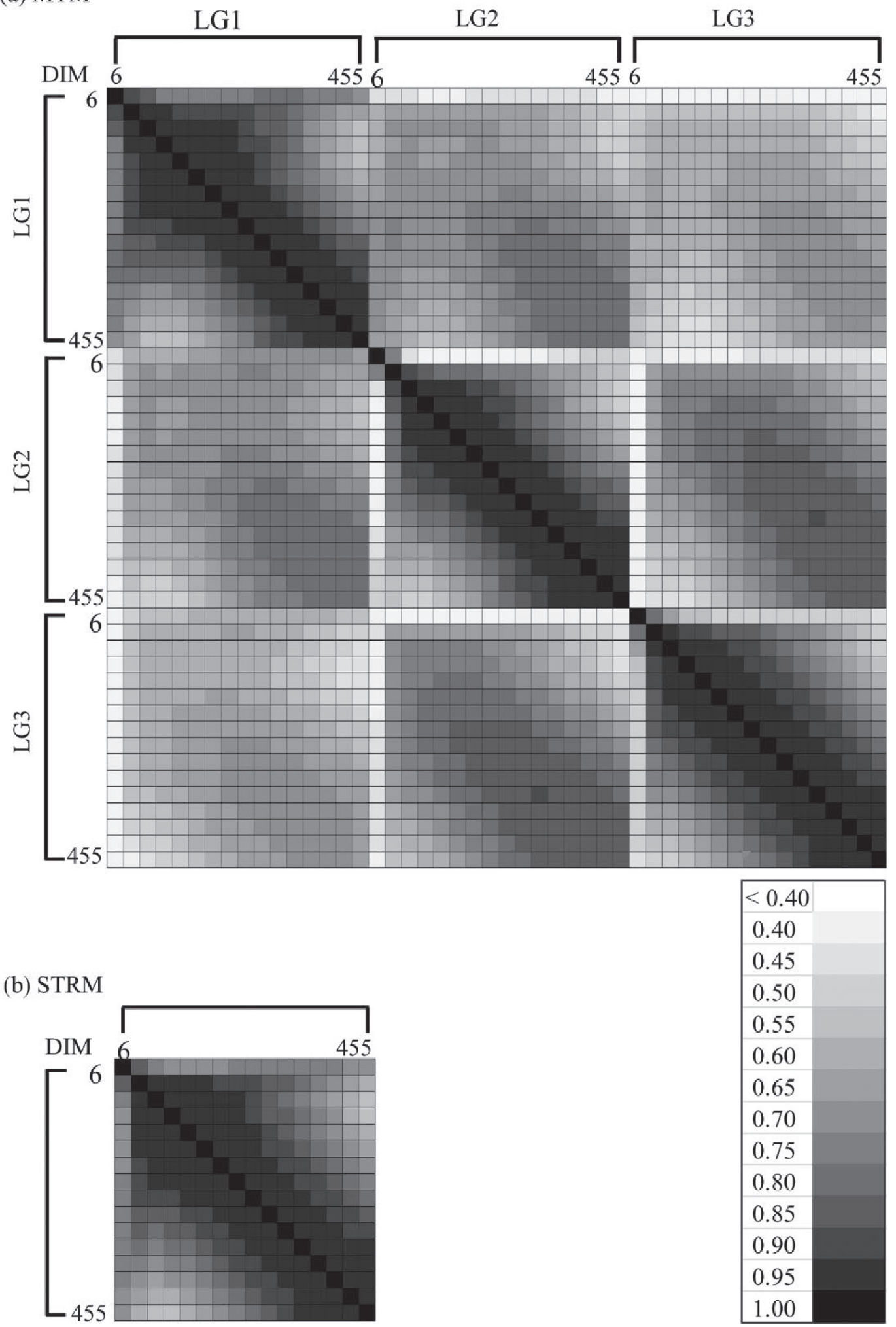

Figure 5. Contour plots of the estimated genetic correlation matrices between pairs of DIM. The genetic correlations of the cumulative pseudo-survival rate were estimated at 6 DIM and once every $30 \mathrm{~d}$ from 35 to 455 DIM. (a) Estimated genetic correlation between the DIM within and among lactation groups (LG1 = first lactation; LG2 $=$ second lactation; LG3 = third to fifth lactations), obtained using the multiple-trait animal model for random regression (MTM). (b) Estimated genetic correlation between the DIM calculated using the single-trait repeatability animal model for random regression (STRM). 
Table 2. Average and standard deviations of the scale $\left(\lambda_{\mathrm{m}}\right)$ and shape $\left(\rho_{\mathrm{m}}\right)$ parameters of the Weibull distribution among the 7 data sets

\begin{tabular}{lcccc}
\hline $\operatorname{Reg}^{1}$ & $\mathrm{LG}^{2}$ & $\mathrm{LP}^{3}$ & $\lambda_{\mathrm{m}}$ & $\rho_{\mathrm{m}}$ \\
\hline 1 & 1 & 1 & $0.00011 \pm 0.00001$ & $0.829 \pm 0.030$ \\
2 & 1 & 1 & $0.00015 \pm 0.00005$ & $0.943 \pm 0.087$ \\
1 & 2 & 1 & $0.00041 \pm 0.00003$ & $1.035 \pm 0.027$ \\
2 & 2 & 1 & $0.00039 \pm 0.00008$ & $1.047 \pm 0.104$ \\
1 & 3 & 1 & $0.00068 \pm 0.00003$ & $0.979 \pm 0.019$ \\
2 & 3 & 1 & $0.00072 \pm 0.00008$ & $7.017 \pm 0.145$ \\
1 & 1 & 2 & $0.00197 \pm 0.00001$ & $8.578 \pm 0.897$ \\
2 & 1 & 2 & $0.00201 \pm 0.00004$ & $6.516 \pm 0.208$ \\
1 & 2 & 2 & $0.00215 \pm 0.00001$ & $5.952 \pm 0.467$ \\
2 & 2 & 2 & $0.00209 \pm 0.00001$ & $6.227 \pm 0.317$ \\
1 & 3 & 2 & $0.00224 \pm 0.00001$ & \\
2 & 3 & $0.00223 \pm 0.00002$ & \\
\hline
\end{tabular}

${ }^{1}$ Region $(1=$ Hokkaido; $2=$ other regions in Japan).

${ }^{2}$ Lactation group ( $1=$ first lactation; $2=$ second lactation; $3=$ third to fifth lactations $)$.

${ }^{3}$ Lactation period $(1=6-255 \mathrm{~d}$ in milk; $2=256-455 \mathrm{~d}$ in milk).

[8] were not significantly different from zero, the EBV of the RR and those at $65,95,155,305,365$, and 455 DIM can be considered to be unbiased estimates of the genetic trend.

In DATA2010, the number of sires that had 30 or more daughters up to the fifth lactation was 482 . In the STRM and PHM, the average $( \pm \mathrm{SD})$ and median numbers of daughters of these sires were $216 \pm 335$ and 97 , respectively. The average numbers $( \pm \mathrm{SD})$ of daughters of these sires in LG1, LG2, and LG3 were $36 \pm 58,50 \pm 81$, and $131 \pm 219$, and the median numbers were 16,20 , and 52 , respectively. Because the records of the daughters were divided into each lactation group of the MTM, the number of daughters in each lactation group of the MTM was smaller than that of the STRM and PHM. Furthermore, because a cow at later parity is necessarily older than one at earlier parity, the number of culled daughters of a sire was largest in LG3, followed by LG2 and LG1. The average reliability values of the EBV of daily PSR during the lactation period, calculated for sires with more than 30 daughters, are shown in Figure 6. The reliabilities of LG2 and LG3 were lower than that of LG1 during the first few days after calving, and then increased and exceeded the reliability of LG1. The reliability of LG3 was the highest of the lactation groups after 33 DIM ( $P$ $<0.05$ ), whereas the reliability of LG1 was the lowest of the lactation groups after 63 DIM $(P<0.05)$. The reliability of LG3 was higher than that of LG2 until 300 DIM $(P<0.05)$, and then the difference between these groups became small. The reliability of the STRM was higher than that of LG1 after 17 DIM $(P<0.05)$, and it was higher than that of LG3 until 31 DIM and that of LG2 until 88 DIM $(P<0.05)$. The averages $( \pm \mathrm{SD})$ of the reliability of the EBV of PSR at 305 DIM among the sires in LG1, LG2, LG3, and the STRM were 0.47 $\pm 0.14,0.58 \pm 0.17,0.60 \pm 0.18$, and $0.53 \pm 0.18$ respectively; these averages at 365 DIM were $0.47 \pm$ $0.14,0.57 \pm 0.17,0.59 \pm 0.18$, and $0.52 \pm 0.18$, and at 455 DIM were $0.43 \pm 0.13,0.53 \pm 0.16,0.55 \pm 0.18$, and $0.48 \pm 0.17$, respectively. The average $( \pm \mathrm{SD})$ of the reliability of the EBV of the RR among the sires was $0.67 \pm 0.17$.

Table 3 lists the absolute values of Spearman's correlation coefficient among the EBV of PSR in LG1, LG2, LG3, and the STRM, and of the RR in the PHM. The correlation coefficients among PSR were positive, and those between PSR and RR were negative. Highly negative correlations between PSR and RR indicate the same sires because the PSR reflects survivability and the $\mathrm{RR}$ reflects cull risk, and therefore absolute values of the correlations are presented. The absolute values of the correlation coefficients between the STRM and the other models ranged from 0.82 to 0.96 , which were higher than those of other pairs. The standardized EBV (EBV divided by the square root of the additive genetic variance of each trait) were used for comparison among the genetic trends of LG1, LG2, LG3, and the STRM (Figure 7a). The genetic trends determined for PSR at 365 DIM of the sires in LG3 and the STRM were flat from 1984 to 1990, decreased in 1991 and 1992, and increased thereafter. The genetic trend for PSR at 365 DIM of the sires in LG1 and LG2 decreased from 1984 to 1992, and increased thereafter. The genetic trend of the standardized EBV of RR of the sires in the PHM decreased from 1984 to 1990, increased in 1991 and 1992, and decreased thereafter (Figure 7b).

\section{DISCUSSION}

Previous studies have shown that the hazard value during early DIM in each parity was as low as 0.0003 to 


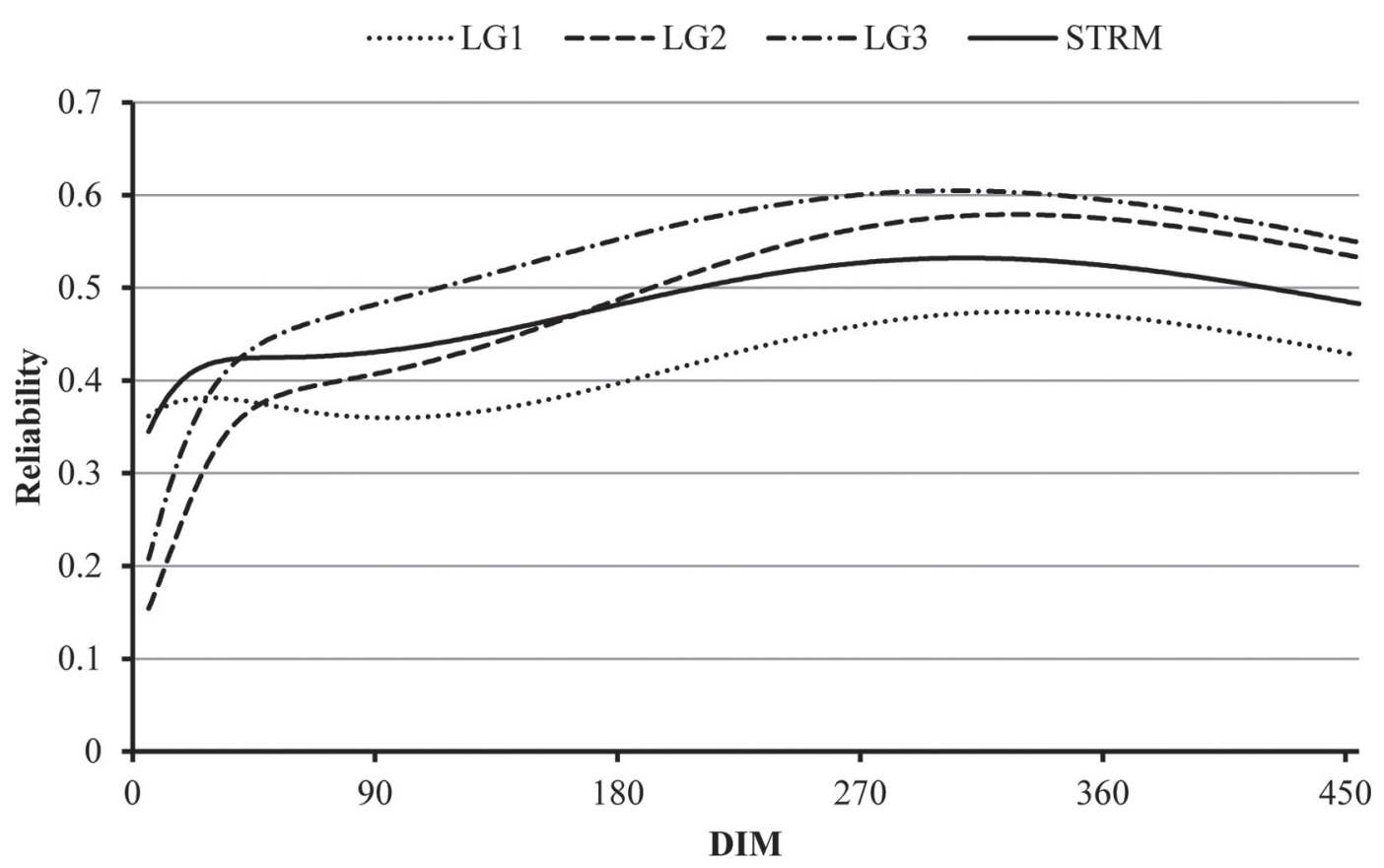

Figure 6. Average of the reliabilities of cumulative pseudo-survival rate of sires with more than 30 recorded daughters, calculated using the multiple-trait animal model for random regression (LG1 = first lactation; LG2 $=$ second lactation; LG3 = third to fifth lactations) and the single-trait repeatability animal model for random regression (STRM).

0.0005 , and increased from 250 to 280 DIM (Ducrocq, 2002, 2005; Terawaki and Ducrocq, 2009). Similarly, previous studies have revealed that the plot of $\{\ln [-$ $\ln ($ survival function)]\} typically shows a mostly linear increase up to 150 DIM, with a more rapid increase thereafter (Roxström et al., 2003; Holtsmark et al., 2009). When the plot of $\{\ln [-$ (survival function) $]\}$ against $\ln$ (time) is approximately straight, the Weibull model is appropriate for the survival data. Furthermore, the parallel curves of the plots among different conditions indicated that their calculated hazards are also proportional. Caraviello et al. (2004b) reported that the cumulative survival rate of Holstein sires decreased with increasing DIM. In this study, the trend of PSR during the lactation period was similar to these trends in previous studies.

In this study, the heritability estimates for PSR were higher in LG2 and LG3 than in LG1, except in the early lactation period. Sewalem et al. (2007) also reported that the heritability estimates of survival traits were higher in later parity than in earlier parity, and Veerkamp et al. (2001) reported that the heritability estimate of survival traits was higher in the first lactation than in the second and third lactations. Previous studies have shown that the heritability estimate of a binary trait was higher when using a threshold model than when using a linear model (Heringstad et al.,
2000; Carlén et al., 2006). Conversely, the correlation coefficient calculated for the EBV of a sire between the threshold and linear models was almost 1, which indicated that the advantage of using the threshold model compared with the linear model is limited (Meijering, 1985; Boettcher et al., 1999; Vazquez et al., 2009). In simulation studies, the theoretical accuracies calculated for linear models tended to agree with the true values, whereas those calculated for threshold models were markedly higher than the true values (Carlén et al., 2006). Boettcher et al. (1999) and Wolf et al. (2010) reported that the magnitudes of selection responses of the sires when using the EBV of the threshold and linear model were similar, and these researchers further suggested that the linear model was suitable for estimating the selection response of the sire because it is computationally favorable. Therefore, we used a linear model to analyze the PSR in this study. Veerkamp et al. (2001) reported that the quadratic function was sufficient for explaining the genetic variation in survival, and no significant difference was observed in the likelihood between the quadratic and cubic models. In this study, only small changes in the estimates of daily additive genetic variance were observed when the quadratic regression coefficient was not considered in the additive genetic effect function. Therefore, considering that the effect of the cubic regression coefficient of the additive 


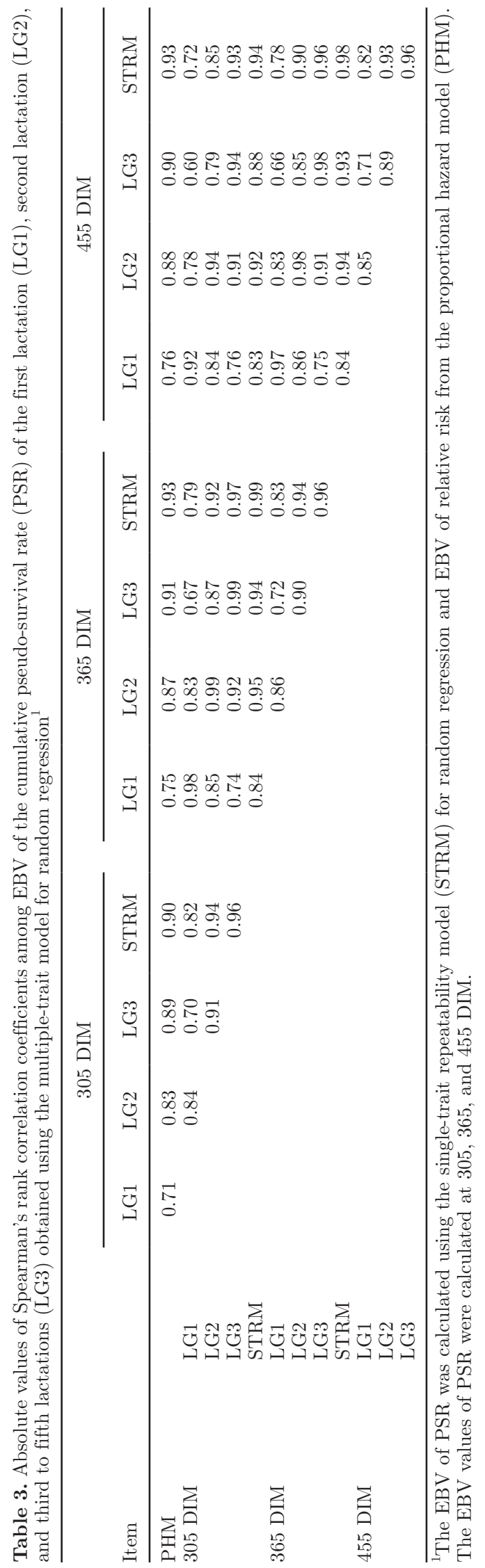

genetic effect would be equally small when estimating PSR, the quadratic regression model was deemed to be adequate.

Sewalem et al. (2007) reported that the genetic correlations of survival among 120 DIM, 240 DIM, and the last day of the first lactation were high (0.94-0.98). In this study, the genetic correlations of PSR were high when the DIM intervals were below $120 \mathrm{~d}$, but decreased when the intervals were any larger. Previous studies reported that the genetic correlations between the first, second, and third lactations ranged from 0.69 to 0.94 , and were higher between consecutive lactations than between the other pairs (Veerkamp et al., 2001; Sewalem et al., 2007). The same trend was indicated in this study. Furthermore, Dürr et al. (1997) reported that within each reason for culling, the annual trend of culling rate showed no variation among lactations. In this study, the genetic correlations of PSR between 2 consecutive parities were higher in the same lactation period than between those in the distant lactation periods in each parity, and this trend was clear after the mid-lactation period. These results showed that the contributions of the genetic factors of survival traits were similar between different lactations for the same lactation stage, but differed between distant stages of lactation even if these parities were same. A few previous studies indicated that several of the reasons for culling cows differed between distinct lactation periods (Dohoo and Waynemartin, 1984; Rajala-Schultz and Gröhn, 1999). Therefore, the genetic relationships of the survival trait between different lactation periods appear to decrease with an increase in the interval between lactation periods. In this respect, the repeatability model, in which the records of distinct lactation numbers were treated as a repeated measure, would be appropriate because the genetic correlation between different lactations was high when the lactation periods were the same.

The reliability of the STRM was similar to that of LG2 and was higher than that of LG1, even though the heritability estimate of the STRM was similar to that of LG1 and lower than that of LG2. Because the number of daughters from sires in the STRM was larger than that in each lactation group of the MTM, the reliability of the PSR of sires was higher even though the heritability was low. The Spearman's rank correlation coefficient of the EBV of PSR was higher between the STRM and each lactation group of the MTM than between each pair of lactation groups within the MTM. This result indicated that the EBV of PSR of the STRM could represent the genetic ability for survival in the case of all lactations. 


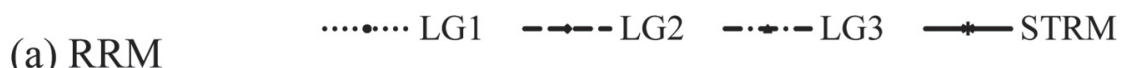

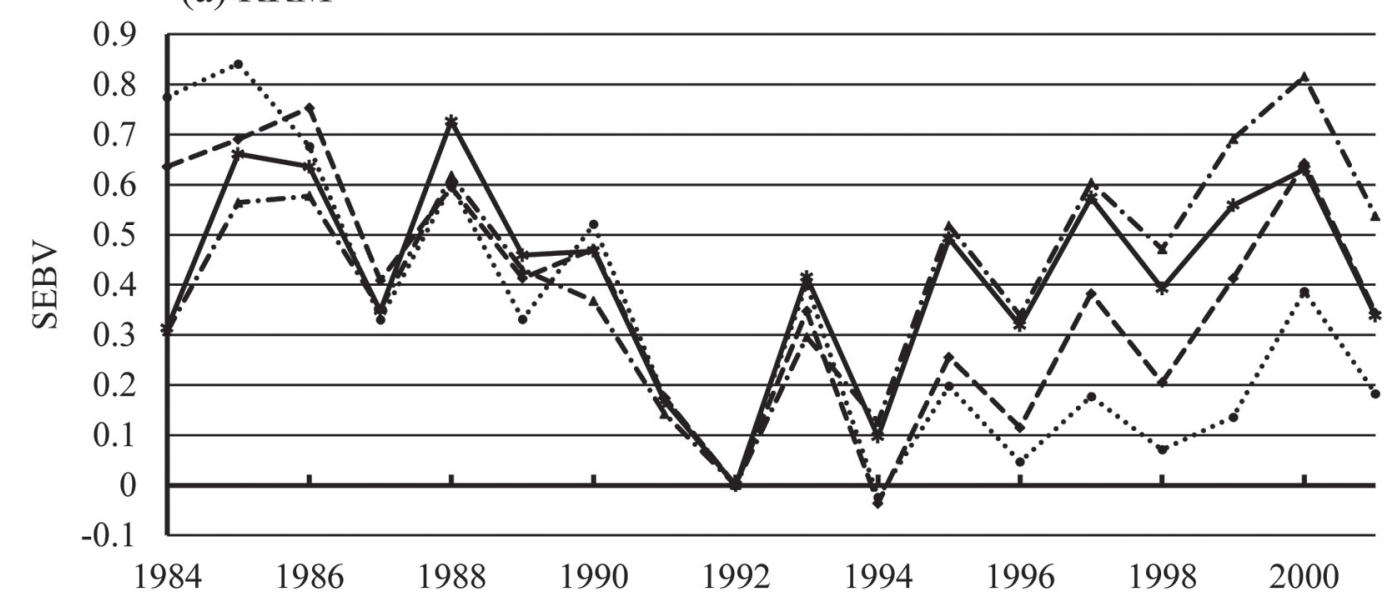

(b) PHM

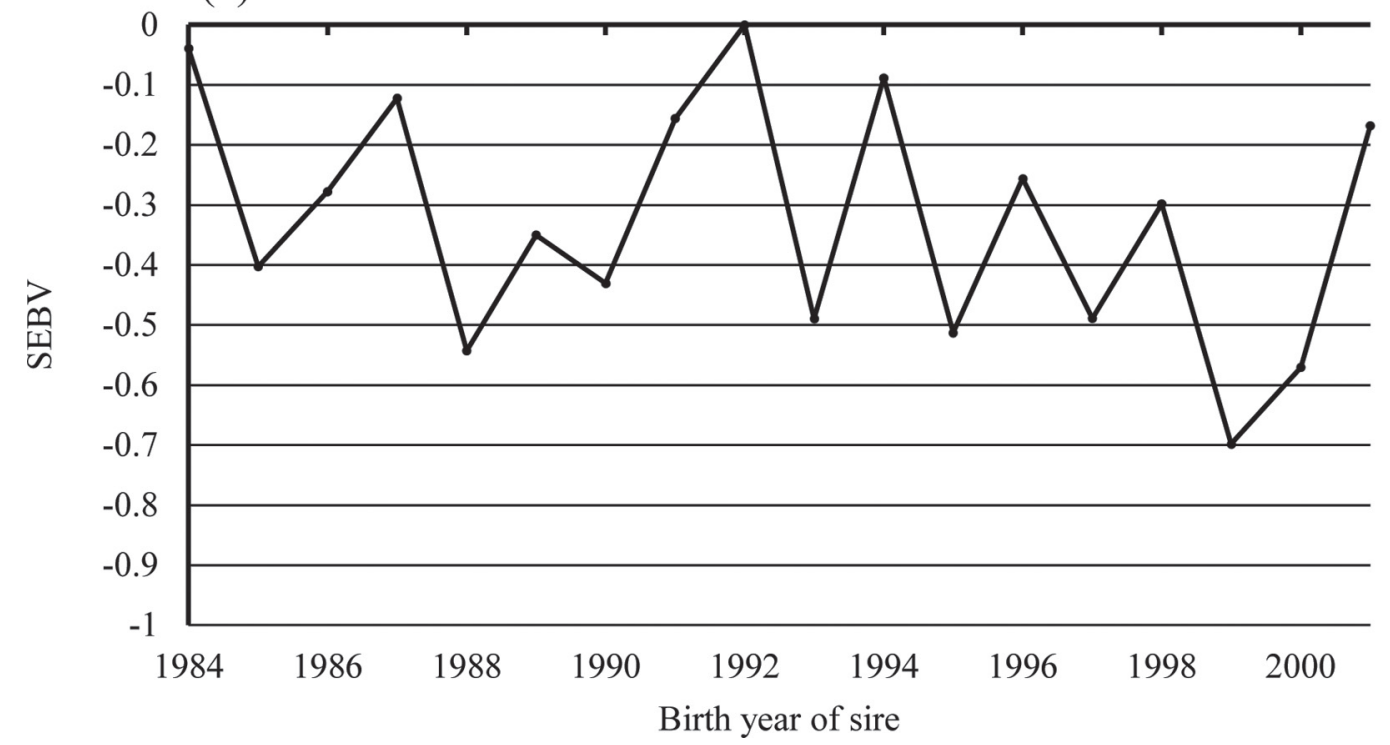

Figure 7. Trends of the standardized estimated breeding value (SEBV) of sires with more than 30 recorded daughters. The average at 1992 was used as the baseline. (a) The SEBV of the cumulative pseudo-survival rate at 365 DIM calculated according to the random regression model $(\mathrm{RRM})$, as determined using the multiple-trait animal model (LG1 = first lactation; LG2 = second lactation; LG3 = third to fifth lactations) and the single-trait repeatability animal model (STRM). (b) The SEBV of relative risk, calculated using the proportional hazard model (PHM).

Previous studies performed using a piecewise Weibull baseline have reported that the $\hat{\mathrm{h}}_{\mathrm{s} \text {,eff }}^{2}$ values of the PHM were in the range of 0.108 to 0.150 (Ducrocq, 2002, 2005; Roxström et al., 2003; Sewalem et al., 2005). Terawaki and Ducrocq (2009) reported that the $\hat{\mathrm{h}}_{\mathrm{s}, \text { eff }}^{2}$ obtained using a piecewise Weibull baseline in Holsteins in the Hokkaido region of Japan ranged from 0.046 to 0.134. Moreover, Sasaki et al. (2012) reported that the $\hat{\mathrm{h}}_{\mathrm{s}, \mathrm{eff}}^{2}$ obtained using a unique Weibull baseline in Holsteins in Japan ranged from 0.101 to 0.105 . The same estimates in this study were lower than those obtained in the previous studies. We compared the results of the RRM with the results of the PHM to determine whether or not the EBV of PSR of the RRM could accurately indicate the genetic ability for survival. The Spearman's rank correlation coefficients between the EBV of PSR in the MTM and the EBV of RR in the PHM increased with increasing lactation numbers. In a simulation study conducted by Jamrozik et al. (2008), the reported correlation coefficients between the EBV from the RRM and PHM at the endpoints of the first, second, and third lactations were $0.81,0.89$, and 0.92 , respectively, when the heritability was assumed to be 
0.050 and the minimum number of daughters was assumed to be 100 . The values of the correlation coefficients of the MTM obtained in this study agreed closely with these previously reported values, and the correlation coefficient of the EBV of the PHM was larger with the STRM than with the MTM. The desirable directions of changes of the EBV of PSR and RR were opposite because the PSR reflects survivability and the RR reflects cull risk. Therefore, the genetic trend of the RR in the PHM was similar to that of PSR at 365 DIM in LG3 and the STRM. These results indicated that the genetic factors contributing to the RR in the PHM would be more similar to the factors that contribute to the PSR in LG3 and the STRM than in LG1 and LG2. However, the genetic correlation and rank correlation coefficients in LG1 were lower than those in LG2, LG3, the STRM, and the PHM, which indicates that survival at LG1 is affected by genetic factors that differ from those affecting survival at other parities.

\section{CONCLUSIONS}

We considered the EBV of PSR to be capable of accurately representing the genetic ability for survival because its correlation coefficient with the EBV of the $\mathrm{RR}$ was high and because the genetic trend was similar to that of the RR. Because the EBV of PSR represents an unbiased estimate of the genetic trend, it is expected to provide stable genetic estimates. The rank of sires in the STRM was similar to that in each lactation group of the MTM. The results of the PHM agreed more closely with the results of the STRM than with the results of the MTM. Because the rank of the matrix, the computing time, and the memory required for calculation are smaller in the STRM than in the MTM, the STRM provides a comparatively easier method for estimating EBV. Collectively, these results showed that the STRM is a more appropriate model than the MTM for determining the EBV for survival of lactating cows.

\section{ACKNOWLEDGMENTS}

In this study, we used the supercomputer at the Agriculture, Forestry and Fisheries Research Information Technology Center, Ministry of Agriculture, Forestry and Fisheries, Tsukuba, Japan.

\section{REFERENCES}

Boettcher, P. J., L. K. Jairath, and J. C. M. Dekkers. 1999. Comparison of methods for genetic evaluation of sires for survival of their daughters in the first three lactations. J. Dairy Sci. 82:1034-1044.
Boichard, D., B. Bonaiti, A. Barbat, and S. Mattalia. 1995. Three methods to validate the estimation of genetic trend for dairy cattle. J. Dairy Sci. 78:431-437.

Caccamo, M., R. F. Veerkamp, G. de Jong, M. H. Pool, R. Petriglieri, and G. Licitra. 2008. Variance components for test-day milk, fat, and protein yield, and somatic cell score for analyzing management information. J. Dairy Sci. 91:3268-3276.

Calus, M. P. L., J. J. Windig, and R. F. Veerkamp. 2005. Association among descriptors of herd management and phenotypic and genetic levels of health and fertility. J. Dairy Sci. 88:2178-2189.

Caraviello, D. Z., K. A. Weigel, and D. Gianola. 2004a. Comparison between a Weibull proportional hazard model and a linear model for predicting the genetic merit of US Jersey sires for daughter longevity. J. Dairy Sci. 87:1469-1476.

Caraviello, D. Z., K. A. Weigel, and D. Gianola. 2004b. Prediction of longevity breeding values for US Holstein sires using survival analysis methodology. J. Dairy Sci. 87:3518-3525.

Carlén, E., U. Emanuelson, and E. Strandberg. 2006. Genetic evaluation of mastitis in dairy cattle using linear models, threshold models, and survival analysis: a simulation study. J. Dairy Sci. 89:4049-4057

Dohoo, I. R., and S. Waynemartin. 1984. Disease, production and culling in Holstein-Friesian cows. Prev. Vet. Med. 2:771-784.

Ducrocq, V. 2002. A piecewise Weibull mixed model for the analysis of length of productive life of dairy cows. Page 505-508 in Proc. the 7th World Congress on Genetics Applied to Livestock Production, Vol. 32, 19-23 August, INRA, Montpellier, France.

Ducrocq, V. 2005. An improved model for the French genetic evaluation of dairy bulls on length of productive life of their daughters. J. Dairy Sci. 80:249-256.

Ducrocq, V., J. Sölkner, and G. Mészáros. 2010. Survival Kit v6-A software package for survival analysis. In Proc. 9th World Congress on Genetics Applied to Livestock Production, Communication 02-32. CD-ROM, August 1-6. German Society for Animal Science, Leipzig, Germany.

Dürr, J. W., H. G. Monardes, R. I. Cue, and J. C. Philpot. 1997. Culling in Quebec Holstein herds. 2. Study of phenotypic trends in reasons for disposal. J. Anim. Sci. 77:601-608.

Essl, A. 1998. Longevity in dairy cattle breeding: A review. Livest. Prod. Sci. 57:79-89.

Gill, G. S., and F. R. Allaire. 1976. Genetic and phenotypic parameters for a profit function and selection method for optimizing profit in dairy cattle. J. Dairy Sci. 59:1325-1333.

Heringstad, B., G. Klemetsdal, and J. Ruane. 2000. Selection for mastitis resistance in dairy cattle: A review with focus on the situation in the Nordic countries. Livest. Prod. Sci. 64:95-106.

Holtsmark, M., B. Heringstad, and J. Ødegård. 2009. Predictive abilities of different statistical models for analysis of survival data in dairy cattle. J. Dairy Sci. 92:5730-5738.

Jamrozik, J., J. Fatehi, and L. R. Schaeffer. 2008. Comparison of models for genetic evaluation of survival traits in dairy cattle: a simulation study. J. Anim. Breed. Genet. 125:75-83.

Liu, Z., F. Reinhardt, A. Bünger, L. Dopp, and R. Reents. 2001. Application of a random regression model to genetic evaluations of test day yields and somatic cell score in dairy cattle. Pages 159-166 in Proc. of the 2001 Interbull meeting, Interbull Bulletin No. 27, 30-31 August, Budapest, Hungary.

Liu, Z., F. Reinhardt, A. Bünger, and R. Reents. 2004. Derivation and calculation of approximate reliabilities and daughter yield-deviations of a random regression test-day model for genetic evaluation of dairy cattle. J. Dairy Sci. 87:1896-1907.

Meijering, A. 1985. Sire evaluation for calving traits by best linear unbiased prediction and nonlinear methodology. Z. Tierzüchtg. Züchtgsbiol. 120:95-105.

Misztal, I., S. Tsuruta, T. Strabel, B. Auvray, T. Druet, and D. H. Lee. 2002. BLUPF90 and related programs (BGF90). Pages $743-744$ in Proc. of the 7th World Congress on Genetics Applied to Livestock Production, Vol. 33, 19-23 August, INRA, Montpellier, France.

Rajala-Schultz, P. J., and Y. T. Gröhn. 1999. Culling of dairy cows, Part I. Effect of diseases on culling in Finnish Ayrshire cows. Prev. Vet. Med. 41:195-208. 
Roxström, A., V. Ducrocq, and E. Strandberg. 2003. Survival analysis of longevity in dairy cattle on a lactation basis. Genet. Sel. Evol, 35:305-318.

SAS Institute Inc. 2004. SAS/STAT ${ }^{\circledast} 9.1$ User's Guide. SAS Institute Inc., Cary, NC.

SAS Institute Inc. 2006. Base SAS $^{\circledR}$ 9.1.3 Procedures Guide, Second Edition. SAS Institute Inc., Cary, NC.

Sasaki, O., M. Aihara, K. Hagiya, A. Nishiura, K. Shii, and M. Satoh. 2012. Genetic evaluation of the longevity of the Holstein population in Japan using a Weibull proportional hazard model. Anim. Sci. J. 83:95-102.

Sewalem, A., G. J. Kistemaker, V. Ducrocq, and B. J. Van Doormaal. 2005. Genetic analysis of herd life in Canadian dairy cattle on a lactation basis using a Weibull proportional hazards model. J. Dairy Sci. 88:368-375.

Sewalem, A., F. Miglior, and G. J. Kistemaker. 2010. Analysis of the relationship between workability traits and functional longevity in Canadian dairy breeds. J. Dairy Sci. 93:4359-4365.

Sewalem, A., F. Miglior, G. J. Kistemaker, P. Sullivan, G. Huapaya, and B. J. Van Doormaal. 2007. Modification of genetic evaluation of herd life from a three-trait to a five-trait model in Canadian dairy cattle. J. Dairy Sci. 90:2025-2028.

Tarrés, J., J. Piedrafita, and V. Ducrocq. 2006. Validation of an approximate approach to compute genetic correlations between longevity and linear traits. Genet. Sel. Evol. 38:65-83.

Terawaki, Y., and V. Ducrocq. 2009. Nongenetic effects and genetic parameters for length of productive life of Holstein cows in Hokkaido, Japan. J. Dairy Sci. 92:2144-2150.
VanRaden, P. M., and G. R. Wiggans. 1995. Productive life evaluations: Calculation, accuracy, and economic value. J. Dairy Sci. 78:631-638.

Vazquez, A. I., D. Gianola, D. Bates, K. A. Weigel, and B. Heringstad. 2009. Assessment of Poisson, logit, and linear models for genetic analysis of clinical mastitis in Norwegian Red cows. J. Dairy Sci. 92:739-748

Veerkamp, R. F., S. Brotherstone, B. Engel, and T. H. E. Meuwissen. 2001. Analysis of censored survival data using random regression models. Anim. Sci. 72:1-10.

Weigel, D. J., B. G. Cassell, I. Hoeschele, and R. E. Pearson. 1995 Multiple-trait prediction of transmitting abilities for herd life and estimation of economic weight using relative net income adjusted for opportunity cost. J. Dairy Sci. 78:639-647.

Wolf, J., M. Wilfová, and M. Štípková. 2010. A model for the genetic evaluation of number of clinical mastitis cases per lactation in Czech Holstein cows. J. Dairy Sci. 93:1193-1204.

Yazdi, M. H., P. M. Visscher, V. Ducrocq, and R. Thompson. 2002. Heritability, reliability of genetic evaluation and response to selection in proportional hazard models. J. Dairy Sci. 85:1563-1577.

Zavadilová, L., E. Němcová, and M. Štípková. 2011. Effect of type traits on functional longevity of Czech Holstein cows estimated from a Cox proportional hazard model. J. Dairy Sci. 94:40904099 . 